\title{
Historia social y literatura en Colombia a comienzos del siglo XX. Los sectores sociales medios en la novela Cosme de José Félix Fuenmayor
}

\author{
por
}

\author{
Sergio Paolo Solano D.* \\ Roicer Flórez Bolívar**
}

Universidad de Cartagena de Indias

Basado en el método indicial propuesto por Carlos Ginzburg este artículo se centra en la novela Cosme para analizar aspectos del contexto social que subyace en la obra. Desde los círculos concéntricos exteriores formados por lo poco que conocemos sobre la vida de José Félix Fuenmayor, los autores se desplazan hasta el mundo de los personajes de la novela, mostrando que en esta existen ciertos aspectos muy allegados a la vida personal y familiar del autor. Reconstruyen algunos aspectos del tejido sociocultural de la Barranquilla de comienzos del siglo $X X$, en especial de unas capas medias organizadas alrededor de un estilo de vida en el que la proyección de una imagen valorada socialmente era esencial.

Palabras Clave: Novela; historia; estilos de vida; honor; capitalismo; capas medias; oficios artesanales; Barranquilla.

* Profesor Asociado del Programa de Historia, Facultad de Ciencias Humanas, Universidad de Cartagena de Indias, Colombia. Miembro del grupo de investigaciones Frontera, Sociedad y Cultura en el Caribe y Latinoamérica (categoría A-1 en clasificación de Colciencias). ssolanod@unicartagena.edu.co.

** Profesor Asistente del Programa de Historia, Facultad de Ciencias Humanas, Universidad de Cartagena de Indias, Colombia. Miembro del Grupo de Investigaciones Frontera, Sociedad y Cultura en el Caribe y Latinoamérica. rflorezb@unicartagena.edu.co 


\section{PRESENTACIÓN}

En una modesta edición realizada en Bogotá en 1927 vio la luz pública la novela Cosme de José Félix Fuenmayor. Oriundo de Barranquilla, ciudad de la región Caribe colombiana, Fuenmayor (1885-1966) alcanzó el reconocimiento nacional e internacional solo en los tres últimos decenios del siglo XX, debido al auge tomado por la obra de Gabriel García Márquez y por los estudios sobre el llamado "Grupo de Barranquilla», formado por intelectuales en los años 1950 y la siguiente década ${ }^{1}$. Hasta entonces su obra había sido opacada por el auge de las novelas Pax de Lorenzo Marroquín (1900) y La Vorágine de José Eustasio Rivera (1924), las que concentraban la atención del mundo letrado colombiano.

El escaso interés que despertó la obra de este autor se debió a que estaba en contravía con las expectativas de los lectores de un país que, después de la guerra de los Mil Días (1899-1902) y de la separación de Panamá (1903), se esforzaba por afirmar una mentalidad pragmática sobre la vida, los estudios y la vida intelectual, achacando buena parte de sus males al apego de los intelectuales y políticos a la escolástica especulativa y al doctrinarismo político. En consecuencia, poetas, gramáticos, clasicistas y latinistas, que habían estado en el centro de la vida política nacional, regional y local, fueron vistos como los culpables el atraso del país ${ }^{2}$.

Solo hasta mediados del decenio de 1970 fue que se rastrearon algunas facetas de la creación literaria de Fuenmayor en la producción literaria de García Márquez. Luego las investigaciones sobre aquel autor adquirieron independencia con relación a las del segundo, lo que ha permitido señalar tres aportes de Fuenmayor a la literatura colombiana. 1) En contraste con las mencionadas novelas contemporáneas, se considera que Cosme inauguró la recreación literaria del mundo social urbano colombiano ${ }^{3}$. 2) Al versar sobre el mundo urbano fue la primera novela en tratar las relaciones entre los hombres, convirtiéndose en un proyecto pedagógico que relaciona los valores familiares en que crece el personaje y el medio social que estaba cambiando rápidamente 4 . 3) $\mathrm{La}$

\footnotetext{
1 Fuenmayor, 1978. Gilard, 50/128-129 (Pittsburgh, 1984): 906-935; 1989: 175-231.

2 Deas, 1993: 25-60. Brown, 30 (Bogotá 1995): 5-25. Solano, 4 (Cartagena, 1996): 61-76. Padilla, 2008.

3 Lejos del mar (Víctor M. García Herreros, 1921), Náufragos en la tierra (Gregorio Castañeda Aragón, 1923), La Vorágine (José Eustacio Rivera, 1924), Quibdó (Pedro Sondereguer, 1927), La Marquesa de Yolombó (Tomás Carrasquilla, 1927) y Tóa (César Uribe Piedrahíta, 1933), fueron novelas que recrearon las relaciones del hombre con la naturaleza. Williams, 1991: 135-143. Bacca, 1998: 45-81. Pöppel, 2000: 14, 178. Guerrieri, 2004: 268-302.

4 Ardila, 2005: 382-290. Ortega, 17 (Barranquilla, 2004).
} 
obra recrea de manera hábil el contexto social y cultural de la ciudad de Barranquilla del decenio de 1920, una sociedad sometida a tensiones entre los elementos modernos que estaban surgiendo y los hábitos y costumbre sociales de corte tradicional de sus habitantes ${ }^{5}$.

Sin embargo, creemos que lo dicho hasta el momento sobre el tercer aporte no ha agotado el tema, y que es posible volver a explorar nuevos aspectos de las relaciones entre la novela y el contexto urbano y social de la época. El ejercicio que nos proponemos realizar es contrastar algunos elementos de la vida de la familia del autor para analizar el contexto social que subyace en la obra, y así indicar que en Cosme están presentes ciertos aspectos muy allegados a la vida personal y familiar de Fuenmayor. Mostramos que la novela permite estudiar las transformaciones operadas en el estilo de vida de los sectores medios o «gente decente» de la sociedad urbana de la región Caribe colombiana debido a los cambios económicos, sociales y culturales que se estaban desarrollando ${ }^{6}$. En esta dirección, seguiremos algunas pistas de la vida del autor que nos permitan, siempre con riesgos, acercarnos a algunas relaciones con su novela. Así, iremos desplazándonos desde los círculos concéntricos exteriores formados por lo poco que conocemos sobre la vida de Fuenmayor hasta el mundo de los personajes de la novela.

En efecto, a través de la historia de la familia de Cosme, Fuenmayor recreó el mundo de algunos sectores sociales que a comienzos del siglo XX vieron desmoronarse parte importante de sus estilos de vida debido a los efectos corrosivos de los avances del capitalismo en esta región. Este redujo la consideración social de que gozaban a los raseros de la rentabilidad y de la riqueza material, al tiempo que no alteró los factores de discriminación y exclusión social del orden social tradicional con el que convivía sin dificultades. El tema no era exótico al mundo de las letras pues ocho años antes de la primera edición de Cosme, el barranquillero Adolfo Sundheim publicó la novela Fruta Tropical (1919), la que también trata sobre la pérdida del mundo valorativo frente a los avances de la mercantilización de todos los aspectos de la vida ${ }^{7}$. Sin embargo, contrario a los personajes padecientes de la novela de Fuenmayor, los de Sundheim representan el mundo de quienes en un contexto de afirmación de la mentalidad del hombre práctico y triunfante, encuentran que valores sociales como el honor, la honradez y la dignidad constituyen obstáculos para poder «triunfar» en la vida. En consecuencia, les es fácil desprenderse de esas valoraciones o acomodarlas a las exigencias del triunfo material, de la

5 Bell, 2, (Barranquilla, 1981): 45-81.

6 Solano, 3/6 (Santa Marta, 2009): 193-213.

7 Sobre este escritor ver: Peña, 17 (Medellín, 2009): 97-119. 
buena vida; el apotegma que orienta la vida del personaje central de Fruta tropical es: «Has dinero honradamente, y si no puedes, has dinero» ${ }^{8}$.

\section{EL CONTEXTO SOCIAL: LOS EMPLEADOS DEL COMERCIO}

En la novela el mundo laboral ocupa un lugar central a través de un discurso sobre las relaciones entre patrón y trabajador, el salario, sobre la movilidad laboral, la justicia y la ética laboral. Las limitaciones de la familia para continuar educando a Cosme, la crisis económica en que cae don Damián, y en consecuencia, las aspiraciones de este para lograr una ocupación decorosa para su joven hijo, llevan a que buena parte de las páginas de la novela de Fuenmayor estén dedicadas al tema del trabajo. También se evidencia la existencia de relaciones entre ciertas ocupaciones laborales, los estilos de vida de sus ejercitantes, y las tensiones a que se vieron sometidas en el contexto del tránsito al capitalismo.

Este aspecto no era ajeno a Fuenmayor, pues en una ciudad centro de actividades portuarias y comerciales, al igual muchos jóvenes de unas capas medias organizadas más por estilos de vida en torno a la prestancia social que por poseer generosos recursos económicos, se aplicó al estudio de los sistemas contables y se convirtió en contador de oficio o juramentado. Esta inclinación se debía a que dada la condición portuaria de sus principales centros urbanos, por las limitaciones de las oportunidades ocupacionales y las actitudes sociales e institucionales frente a la creación intelectual, a lo largo de su historia colonial y republicana en la región costeña las relaciones entre los intelectuales y el comercio fueron frecuentes, en vista de que el tráfico de objetos materiales también movilizaba libros e ideas. Miembros de familias prestantes atraídos por el estudio en una época en que se valoraba el conocimiento como señal de distinción, crecieron detrás de los mostradores de las casas comerciales en calidad de dependientes, contabilistas y administradores, y ahí entablaron intensas relaciones con los empleados de menor rango que luchaban por granjearse la consideración social de los demás.

Fuenmayor había estado cerca de los empleados (en 1910 fue secretario del pequeño Banco Comercial de Barranquilla que dirigía su tío José Fuenmayor Reyes, y luego fue contabilista de casas comerciales) y conocía de los procedimientos utilizados por el capital para arrebatarle los bienes a los deudores imposibilitados para cumplir con las cargas contraídas. Por otra parte, su padre

\footnotetext{
8 Sundheim, 1919: 80-87. Solano, 9 (Cartagena, 2008): 126-145.
} 
fue médico y boticario, y por esta vía estaba relacionando con el mundo de las valoraciones artesanales, pues la botica clasificaba en el ámbito de las artes manuales calificadas y compartía el universo valorativo y las formas de vida de otros oficios que por los conocimientos exigidos y por la nobleza de los materiales con que se trabajaba se granjeaban la consideración social de los demás. Además, el ejercicio del periodismo de oposición, su adscripción al liberalismo, partido que por esos años contaba con sectores militantes que empezaban a recoger toda la inconformidad suscitada por la llamada «cuestión social» de los trabajadores, y su formación intelectual, le permitió conocer las adversidades de gruesas franjas de la población barranquillera.

Finalizando el decenio de 1910 colaboró en la fundación de la Asociación de Empleados de Comercio de Barranquilla (Adeco), organización mutuaria creada con el fin de socorrerse y para resistir las arbitrariedades de los patronos y administradores, hasta tal punto que para finales del siguiente decenio su presidente, Gualberto Barba (originó el nombre de don Barbo, ¿personaje de la novela?), declaraba que el propósito de ese gremio era conseguir un trato justo y digno para los empleados, quienes por sus conocimientos y por el desempeño de cargos de confianza merecían respeto y consideración ${ }^{9}$. Además, a partir de los años de 1920 la sede de la Adeco se convirtió en centro de encuentro de los intelectuales, en espacio de tertulias en el que los ilustrados exponían sus puntos de vistas sobre muchos temas culturales, y porque compartían una visión de la vida social y de la persona muy afín.

Por testimonios directos de viejos empleados de casas comerciales en los años cuarenta y cincuenta del siglo XX y por denuncias que aparecen en la prensa de la época, se infiere que estos soportaban una de las condiciones laborales más adversas entre el sector de los empleados y trabajadores, lo que contrastaba con la posesión de ese capital simbólico representado en sus conocimientos, experiencias, inventivas, seriedad y la honradez. Las luchas reivindicativas adelantadas a comienzos de ese siglo señalan que en muchos casos el vínculo laboral no aparecía como una simple relación económica erigida sobre la independencia de las partes contratantes, resultado a la vez del libre juego entre la oferta y la demanda en el mercado laboral, sino como una relación de dependencia personal del trabajador respecto del empresario o su representante. Puede pensarse que la denominación de «dependientes» que aún hoy día se da a estos trabajadores, es la supervivencia de un vínculo de subordinación que estaba más allá de lo económico. Trabajar en el comercio requería de recomendaciones de personas fiables, lo que creaba compromisos personales entre

9 Don Ramiro, 1928: 122-123. 
el trabajador y su familia y quien lo recomendaba. Mientras que en otras áreas las relaciones laborales podían ser más desenvueltas y solo requerían la certificación del anterior empleador, en el comercio eran más complicadas viéndose los trabajadores sometidos a maltratos y atropellos.

El control del comerciante sobre el reducido número de personas que trabajaban en su almacén era abrumador, tal como se observa en la novela que comentamos. Un periódico de 1910 editado en Magangué, puerto fluvial en ascenso por esos años, describe los esfuerzos de muchos dependientes de casas comerciales como un sostenido esfuerzo de padres e hijo: "Consagrar su hijo al comercio, principiando por la dependencia, el barrido, hechura de paquetes, para que más tarde empiece a aprender contabilidad, liquidar facturas, conocer el giro bancario, las tallas, los mercados... todo...» ${ }^{10}$. Un relato del mulato cartagenero Juan Coronel contenido en su autobiografía editada en Guatemala en 1894, cuenta con detalles los padecimientos de este sector laboral, por lo que vale la pena citarlo en extenso:

Suspendida más tarde la elaboración de fósforos, pasé a sufrir la humillación de mi naciente dignidad, sirviendo como empleado a un comerciante que desconfiaba de cuanto viviera bajo el sol... me despidió de su servicio, por esta ocurrencia: en Cartagena hay el hábito cursi de anteponer el calificativo niño, al nombre del hijo de padres acomodados, y se oye a los criados llamar niño Pedro a un hombrunazo que tiene más pelos en la barba que lanas un borrego. Si algo exaltó siempre mi pacífico carácter, fue esa ridiculez de la aristocracia cartagenera, y al insinuarme el mercader en cuestión, que debía decirle niño Rafael al mayor de sus retoños, le espeté la más calurosa improvisación que ha salido de mis labios contra las pretensiones nobiliarias ${ }^{11}$.

Frente a los maltratos las alternativas que tenía el empleado dependían de la oferta de empleos y de las necesidades del trabajador y del sentido de dignidad del mismo. En muchos casos abandonaba el trabajo, en otros se llenaba de una paciencia bíblica y soportaba estoicamente, y en algunos optaban por lo que hizo Juan Coronel: «Comprendí que necesitaba la fuerza del dinero o la de la instrucción para hacer respetar mis derecho» ${ }^{12}$.

Estas actitudes frente al maltrato era resultado del hecho de que los empleados del comercio, al igual que los pequeños comerciantes, profesionales de extracción humilde, maestros artesanos, media y baja burocracia oficial, pertenecían al nivel medio de la sociedad. Pese a la diversidad de sus orígenes

10 A los padres de familia. Polo Norte. Magangué, septiembre 11 de 1910, Archivo Histórico de Cartagena, Colombia (AHC).

11 Coronel, 1947: 8-9.

12 Coronel, 1947: 9. 
y características este sector se agrupaba en torno a unos estilos de vida valorados socialmente. Las gradaciones en la valoración se debía a que el honor constituía un capital simbólico desigualmente distribuido al también depender de la condición étnica, de la procedencia familiar, la educación, la estimación de los oficios, de la pertenencia a redes políticas y de otros factores. Sin embargo, por encima de estas y de ciertos desniveles en la vida material, diversos sectores sociocupacionales compartían formas de vivir, valoraciones acerca de la vida personal, familiar y pública construidas alrededor de la proyección de una imagen positiva que les granjeaba el respeto y la consideración de los demás ${ }^{13}$.

Hasta donde la investigación histórica arroja luces, los orígenes de este estilo de vida se remontan a la segunda mitad del siglo XVIII cuando sectores de mestizos, negros libres y blancos pobres comenzaron a presionar para que la honorabilidad no fuese medida solo con base en el rasero del nacimiento, es decir, por la limpieza de sangre, la condición étnica blanca y por pertenecer a una familia prestante. Exigían estos sectores que al lado de estas formas tradicionales de prestancia social, también se valorara el esfuerzo personal y familiar de aquellos que llevaban una vida decorosa y construida con esfuerzos, con trabajo. «Hijo de su propio esfuerzo» fue una expresión muy común a lo largo del periodo estudiado para referirse a estas personas. Esos sectores participaron en la lucha por la república con la aspiración de conseguir los espacios que bajo el régimen colonial les costaba ingentes trabajos. La ciudadanía fue la aspiración que los motivó y bajo el diseño de estrategias personales y familiares ${ }^{14}$, abrieron brechas al orden social para permitirse la movilidad social en un sentido muy preciso: salir del estado de indiferenciación social que supone el calificativo de plebeyo y/o popular y ganarse un estatus de reconocimiento y de diferencia.

La existencia de este sector social es evidente a través de una información dispersa y múltiple. Las notas necrológicas aparecidas en la prensa comercial y política de esa centuria exaltan la consideración social que se había granjeado el difunto gracias a la práctica de unos valores y virtudes sociales, entre las que siempre se subraya el hecho de que era hijo de su propio esfuerzo y a una conducta social considerada por los demás como virtuosa y decorosa. Muchas de estas notas se refieren a artesanos, empleados de casas comerciales y de empresas modernas de transporte, oficialidad de vapores fluviales, mecánicos y técnicos, oficialidad media de las milicias, pequeños comerciantes, funcio-

13 Garrido, 1999: 99-121.

14 Helg, 2005: 319-364. Parker, 1995: 161-185. 
narios públicos medios y menores, profesionales de extracción humilde, tipógrafos, boticarios, maestros de escuelas y colegios y otras personas. A muchos de estos a menudo se les tropieza en la prensa oficial de la época ejerciendo cargos públicos por designación o representación; otros resaltan por los rangos de sargentos, tenientes, coroneles, capitanes y en algunos casos generales de las milicias. Firman manifiestos y organizan sociedades políticas y de beneficencia, al tiempo que forman parte de las cofradías religiosas y se les registran en los listados de las logias masónicas.

Otros elevan representaciones ante las autoridades, y con estas contratan la construcción y refacción de bienes muebles e inmuebles públicos. Igualmente rematan pequeños impuestos municipales y provinciales y se les reconoce el respeto social al aceptárseles en calidad de fiadores en los contratos públicos. No pocos hacen de la prensa una tribuna para expresar sus ideas y puntos de vista sobre la situación política y económica y la administración pública. También forman parte de los directorios políticos municipales, provinciales y regionales, y a comienzos del siglo XX se colocan al frente de la protesta y de la organización de los trabajadores. Su influencia en la vida social, cultural y política es más significativa de lo que a menudo se reconoce, hasta el punto de que muchos elementos de sus estilos de vida se constituyeron en el patrimonio de grandes sectores de la población de los principales epicentros urbanos de Colombia, en especial de las modernas capas medias que se fueron formando con el transcurso del siglo XX.

En una sociedad como la del Caribe colombiano que apenas cincuenta años atrás acababa de abolir la esclavitud, y en la que sectores de mestizos y negros libres venían luchando desde la segunda mitad del siglo XVIII para que a la pequeña sociedad de gentes notables pertenecieran no solo a los que gozaban de prestancia por nacimiento y color, sino también quienes por llevar una vida digna y honorable se merecían el reconocimiento y la consideración positiva de los demás, ese capital simbólico personal y familiar diariamente era puesto en entredicho, por lo que quienes lo usufructuaban tenían que defenderlo contra cualquier intento de menoscabo. El recurso de la protesta colectiva y ruidosa para hacer valer esa consideración no era usual entre estos sectores que habían crecido con un profundo temor al escándalo público.

Ahora bien, hasta finales de los años de 1910 los empleados del comercio constituían un grupo laboral muy desarticulado, por lo que su usual forma de protesta asumió la vía individual de abandono del trabajo, la que era propia del mismo mundo social y cultural que compartían los artesanos, dependientes comerciales y trabajadores calificados del transporte y de la naciente moderna industria. En este mundo (al menos en el caso de los sectores de trabajadores «más visibles» que la información disponible nos permiten analizar), la digni- 
dad personal y familiar era una de las columnas vertebrales en torno al cual se anudaban el resto de valoraciones, producto de una independencia que los colocaba en condición de poder contratar y trabajar como personas independientes, ya fuera en sus talleres, a domicilio o en una empresa. Ese cosmos social y cultural se jugaba su suerte a cada rato, y la novela Cosme es un buen retrato de la situación que vivieron algunos sectores de artesanos a comienzos del siglo $\mathrm{XX}^{15}$.

Garantizar la independencia se constituyó en el norte de muchas familias de empleados, artesanos y trabajadores notables, pues ahí estaba el quid de la prestancia y consideración social. La Ley 46 de 1883 del Estado de Bolívar consagraba que para poder ser miembro de jurado de revisión judicial se debía «Tener algún oficio, profesión o industria, que de garantías de independencia personal». Y esto fue así en todas las esferas de la vida pública a lo largo del siglo XIX. Cuando pasaban a la condición de dependientes económicos, se resistían a la subordinación, por lo que en sus exigencias siempre estuvo presente un «trato digno y justo» por parte de los empresarios y sus administradores. Esta fue una de las peticiones centrales de las asociaciones de empleados del comercio de Santa Marta, Cartagena y Barranquilla ${ }^{16}$.

Pues bien, este fue un mundo que conoció muy bien José Félix Fuenmayor al igual que muchos otros escritores colombianos de comienzos del siglo XX que crecieron en los establecimientos comerciales paternos o ajenos, como fueron los casos de Luis Carlos López, Manuel Cervera, Gregorio Castañeda Aragón, Adolfo Sundheim, el catalán Ramón Vinyes, el filósofo Julio Enrique Blanco, Miguel Rasch Isla, Enrique Restrepo, Leopoldo de la Rosa, como también el bogotano Clímaco Soto Borda entre otros. El sabía lo que ahí se padecía, y conocía de los procedimientos fraudulentos de muchos empresarios como lo pone de presente en el caso del empresario Pechuga y del capitán Truco ${ }^{17}$.

Por eso, y por una herencia española que ha puesto de presente el historiador Jaime Jaramillo Uribe, en medio del ambiente cultural de la época de la

15 Don Ramiro, 1928: 6-7. Goenaga, 1953: 10.

16 Recopilación, 1876: 163.

17 Los indicios hacen pensar que algunos personajes de la novela de Fuenmayor los tomó de la realidad social regional. El capitán Truco parece reproducir los comportamientos del empresario cartagenero Juan Bautista Mainero y Trucco, famoso por sus constantes pleitos y problemas con quienes se le acercaban en planes de negocios, y quien a finales del siglo XIX mantuvo una fuerte polémica con Francisco Javier Cisneros a través de las páginas de el periódico El Porvenir por motivo de las luchas portuarias y comerciales entre Cartagena y Barranquilla. Boca, hombre de desmedidas ambiciones parece tomado del empresario Roca, de Barranquilla, quien por los años 1920 montó las importaciones de medicamentos en gran escala, lo que arruinó a los boticarios. 
hegemonía conservadora muchos escritores desarrollaron un claro carácter antiburgués en sus escritos, que los diferencia de lo sucedido en otras partes del mundo donde el empresario se convirtió en héroe. Ello se observa en las novelas A Fuego Lento (1902) del cubano Emilio Bobadilla (Fray Candil), la ya mencionada Fruta Tropical, en Cosme de Fuenmayor, en toda la obra poética de Luis Carlos López o en una obra teatral como Secundino el Zapatero de Candelario Obeso. Por eso, en las obras que ponen en relación al individuo con las tendencias predominantes de la sociedad se puede respirar cierto escepticismo, un aire de desesperanza y de crítica mordaz. Desde la perspectiva del arribista lo planteó muy bien Adolfo Sundheim en su citada novela de 1919 a la que nos hemos referido algunas páginas atrás.

\section{EL CONTEXTO FAMILIAR. LA BOTICA Y EL AMBIENTE INTELECTUAL}

Pero la relación de Fuenmayor con el mundo del pequeño comercio y con el universo simbólico de los artesanos también provenía por el lado de su padre, Heliodoro Fuenmayor Reyes, médico autodidacta, boticario y perteneciente a una familia de liberales radicales que pagaron con cárcel la oposición que ejercieron al régimen regenerador (1886-1899). La formación de Heliodoro Fuenmayor R. en ciencias médicas la debió a que por línea paterna provenía de una familia nativa de Maracaibo (Venezuela) que había sobresalido por la dedicación de sus miembros al estudio. Su padre, el general José Félix Fuenmayor Parra (1827-1916), quien llegó a Barranquilla en 1876 proveniente de Maracaibo, su ciudad natal. En esta ciudad se acreditó la fama de ser un hombre versado en varias disciplinas y de educar a sus hijos con rigor y apegados al estudio.

En una época en que las únicas alternativas que tenían los jóvenes era combinar la dedicación a la jurisprudencia o la medicina con los negocios y la política, Heliodoro Fuenmayor R. ejerció la medicina aprovechando que una ley del Estado de Bolívar expedida en 1882, suprimió los títulos universitarios para el ejercicio de los conocimientos en medicina y abogacía. Cuando para comienzos del decenio de 1890 fue abolida tal liberalidad y se restableció la exigencia del título, no tuvo ningún problema para presentarse ante un jurado de galenos examinadores para que avalaran sus conocimientos y destrezas en el oficio.

Quienes ejercían la medicina en esa época usualmente poseían una botica para preparar los medicamentos recetados a los pacientes. Asimismo, el complemento ideal del apego al cultivo del intelecto era ser publicista, editar un órgano informativo o poseer una imprenta. El padre del autor de Cosme tuvo 
la fortuna de poseer ambos corolarios, y su botica editaba un pequeño boletín que contenía propagandas comerciales, noticias y temas culturales y científicos. Por la descripción hecha por Emilio Bobadilla en su citada novela, ese pequeño negocio era lugar de encuentro de librepensadores, como también debían ser otros talleres, oficinas de profesionales liberales, tiendas y sitios de esparcimiento público, algo muy usual en la época.

Para efectos de estas líneas, es bueno tener presente que las boticas guardaban significativas diferencias con las farmacias actuales, pues quienes las administraban eran personas con conocimientos de medicina, química y herbología, y recetaban los medicamentos que elaboraban. En 1893, con el propósito de aclarar las tarifas de impuestos a los establecimientos comerciales, la gobernación del departamento de Bolívar anotó que se entendía por botica el establecimiento de un boticario, entendido este como «... el profesor de farmacia que prepara y expende las medicinas». No queda claro a que se refiere la disposición de la gobernación cuando asocia el boticario a la condición de «profesor», pero sí debe tenerse presente que el gobernador del momento era Henrique L. Román, hijo de Manuel Román y Picón, propietario de la farmacia y laboratorio Román y profesor de química durante varios años en la carrera de medicina de la Universidad de Cartagena. Es el negocio de esta familia el que se encargó de difundir el concepto de farmaceuta que fue desplazando al de boticario hasta el punto que por el decreto citado se vieron obligados a aclarar este último con fines fiscales ${ }^{18}$.

Aunque a nivel internacional se estaba operando una separación entre el ejercicio de la medicina y la elaboración de medicamento por los boticarios, en Colombia, como en muchas otras partes del mundo, el médico usualmente preparaba los remedios que recomendaba a sus pacientes, o trabajaba de la mano con algunas boticas. En algunas ocasiones los médicos estaban en disputa con los propietarios de estos establecimientos que sin tener aquella condición recetaban. En estos casos las boticas eran unos pequeños laboratorios en los que se preparaban medicamentos, y el oficio y/o profesión estaba cerca de lo que en el lenguaje del antiguo régimen se conocía como bellas artes en la medida en que su dominio requería de una aplicación al aprendizaje de las reglas del arte que al mismo tiempo eran reglas para la vida. En el proceso de aprendizaje y en el ejercicio del oficio que comportaba trabajo manual, el boticario no estaba lejos del mundo de los oficios

18 Qué se entiende por botica, Registro de Bolívar. Cartagena, junio 29 de 1893, AHC; sobre el empleo del concepto de farmaceuta ver Registro definitivo de las personas obligadas a pagar la contribución directa en el distrito de Cartagena, Diario de Bolívar. Cartagena, 4 de abril de 1877, AHC. 
artesanales calificados que se habían granjeado la consideración y el respeto social ${ }^{19}$.

El ambiente de la botica y de la contabilidad de los negocios marcó en varios sentidos a J. F. Fuenmayor. En una carta de su hijo Alfonso a su madre firmada en Bogotá en 1936, se dejan ver los conocimientos de aquel sobre medicamentos y química. Los nombres Damián y Cosme, muy familiares al mundo de los boticarios, corresponden a los patronos de la medicina y de la farmacia. Con toda seguridad que entre los morteros, matraces, pipetas, frascos, los olores de químicos y vegetales, libros y revistas de ciencias y entre las conversaciones de su padre con los contertulios que todas las tardes acudían a la botica, transcurrió la infancia y pubertad del escritor.

De igual manera, las vicisitudes en que se vieron envueltas las boticas de la época también dejaron su impronta en el escritor, pues desde comienzos del siglo XX tuvieron que afrontar la competencia de empresarios que comenzaban a importar drogas alemanas y norteamericanas que se producían en serie. Estas importaciones estimularon la creación de importantes farmacias, como la de la familia Roca, en las que al lado de la producción manual de drogas se comercializaba en grandes cantidades productos farmacéuticos importados gracias a que los años de «prosperidad a debe» permitieron traer gruesas remesas de artículos de drogas patentadas. Estas familias estaban vinculadas a los círculos del poder y para mediados del decenio de 1930 ligaron sus intereses en la afamada firma farmacéutica Blanco y Roca, la que concentró buena parte de la clientela barranquillera ${ }^{20}$, y laboratorio Román en el caso de Cartagena. De todas las farmacias que empezaron a competir con las boticas la más aventajada fue el laboratorio Román que para el penúltimo tránsito finisecular estaba bajo la administración de Henrique L. Román, miembro de los círculos sociales más importantes de la ciudad, político que se había visto favorecido por los gobiernos regeneradores gracias a sus entronques familiares con Rafael Núñez (cuatro veces presidente de Colombia 1882-1894), los Vélez y los de la Vega. Gracias a sus recursos, influencias y solidez de su negocio se consiguió patentes de productos de tocador y de drogas de consumo masivo. Para 1916 ya tenía una enorme ventaja sobre el resto de farmacias y mucho más sobre las boticas cartageneras, produciendo cuarenta y siete especialidades.

A esto hay que agregar que la condición de puertos de importación, la existencia de núcleos de extranjeros, los continuos viajes al exterior y la proximidad del Canal de Panamá (dado al servicio en 1914) con sus hospitales y gale-

19 Sewell, 1992: 37-50.

20 Rivero, 2005: 22-29. García, 2000. 
nos estadounidenses, crearon las condiciones para que sectores de las elites de esta región tuvieran una inclinación por los servicios médicos y las farmacopea extranjera, la que en ese tránsito de siglos comenzaba a vivir una de las transformaciones más significativa gracias a su industrialización que permitió producir drogas en grandes cantidades. Una revisión de la prensa cartagenera y barranquillera del segundo decenio del siglo XX en adelante, muestra que las personas prestantes acudían con mucha facilidad a la zona del canal de $\mathrm{Pa}$ namá para tratarse los achaques de salud de alguna consideración. Todo esto estuvo coronado por unas campañas sistemáticas de la medicina alopática contra la medicina tradicional y la homeopática, la presencia de los estudios de medicina en la Universidad de Cartagena y unos empresarios (algunos de ellos médicos) a la caza de negocios rentables, empezaron a transformar y acorralar a médicos y/o boticarios.

Estas circunstancias ayudaron a introducir gradaciones en el comercio de drogas que iban de los grandes establecimientos que importaban y distribuían drogas extranjeras, preparaban específicos, ungüentos, tónicos y otros remedios, pasando por medianos negocios que no importaban pero si redistribuían los medicamentos que los anteriores les suministraban, hasta llegar a los boticarios tradicionales que con materias primas importadas y plantas medicinales del medio preparaban pociones pata los enfermos que los consultaban. Pues bien, ya para comienzos del siglo XX empresarios de ambos puertos importaban drogas en grandes cantidades y se establecieron farmacias como negocios independientes del ejercicio de la medicina. Precisamente, a finales del decenio de 1920 los Blanco con los Roca Niz se asociaron y crearon la droguería y farmacia Blanco \& Roca que se convirtió en la principal empresa distribuidora de productos en la Costa.

\section{LAS VALORACIONES SOCIALES Y LOS ESTILOS DE VIDA}

Hasta aquí hemos intentando mostrar que la comprensión de la obra se hace mucho más rica cuando se desplaza el lente de análisis hacia la familia de Cosme, pues se manifiesta el mundo social y cultural de la época que no se percibe cuando solo se analiza la relación entre el personaje central y las transformaciones sociales que se estaban operando. El universo social representado en la novela se caracteriza por su fragilidad, pues cualquier persona y su familia podían ser arrojadas por un traspié que colocara en entredicho una honorabilidad lograda con dificultad, con muchos sacrificios y mantenida con mucha desazón. Esta fragilidad es la que sostiene buena parte de la tragedia escenificada en la novela Cosme. Lo primero que salta a los sentidos es que la vida de 
sus progenitores es un rosario de incertidumbres frente al porvenir que espera a su hijo, como también de padecimientos materiales. En medio de una situación profundamente adversa se sumen en un ambiente distópico, en la ausencia de proyectos de vida, y sin oponer resistencia transitan de la condición de «pobres vergonzantes» que soportan todas las privaciones habidas y por haber a la de miserables, distinción de gran valía en la construcción del orden social de ese entonces. No se atreven a declararse «pobres de solemnidad», figura que les hubiese permitido recibir una pequeña caridad de las autoridades municipales, pues las valoraciones que estructuran su forma de vida provienen de un mundo donde el honor y la dignidad son piedras axiales. Las limitaciones solo las conoce el médico Patagato y Surita, la empleada doméstica, quien soluciona las apremiantes necesidades mientras que los patronos están paralizados, inertes frente a las calamidades. Si «orgullo con hambre» y «pobre pero honrado» fueron los apotegmas que durante muchos años orientaron su existencia, ahora comienzan a desmoronarse frente a una fatalidad que los deja en la calle por efecto de una hipoteca sobre la casa y de un préstamo sobre la botica.

Frente a este cuadro de infortunios la única salida que queda es la muerte: doña Ramona se desmorona ineluctablemente y fallece sin tener ninguna conexión con la realidad, don Damián se suicida y Cosme termina por abandonarse por completo ante las desventuras y muere violentamente en una situación absurda. La pérdida de esperanzas y el abandono no era nada nuevo para los sectores sociales que veían como era despedazada esa forma de vida que les granjeaba una consideración social, cayendo en la ausencia de proyectos positivos. En una reciente obra que analiza las variaciones en los discursos del artesanado colombiano de mediados del siglo XIX acorde con los cambios en la situación política y en la correlación de las fuerzas sociales en pugnas en el marco de la aplicación de las reformas liberales, se señala que después de la caída de José María Melo en 1854, sectores importantes de este grupo social se retrotrajeron de la vida pública y en determinadas circunstancias no poseyeron la capacidad para sobreponerse a las circunstancias $\operatorname{adversas}^{21}$.

Ese desaliento fue común entre los miembros del sector de los artesanos notables calificados, de los pequeños comerciantes al menudeo y de profesionales de extracción humilde que no veían prosperar sus negocios, talleres y consultorios, siendo lo más usual vivir en una continua zozobra ante el riesgo de ser empujados cuesta abajo dado que al borde de las puntas de sus pies esta-

21 Gutiérrez, 1995: 97-101. 
ba el precipicio de la miseria, como se observa al leer los poemas de Cosme cuando se percata que la mujer amada se siente atraída por otro joven.

El tema del carácter, de la personalidad, de los atributos morales para «triunfar en la vida» que tiene que ver a contraluz con las características de Cosme, o de cualquier otra novela del tránsito del siglo XIX al XX, estuvo en el centro de las discusiones de la época y sectores de las capas medias de la sociedad colombiana de ese entonces no fueron ajenas. Obras como El propio esfuerzo de Samuel Smiles, traducida al español por el cartagenero Eduardo Gutiérrez de Piñeres, fue moneda corriente en estos sectores a comienzos de la penúltima centuria. Las discusiones disciplinarias de la sicología, la sociología, la literatura, la política, la economía y desde las ideas esotéricas como la masonería, espiritismo y rosacrucismo ${ }^{22}$, apuntaban a señalar la necesidad de formar los aspectos del hombre práctico. Los trabajos de Max Nordeau, Alan Kardec, Maximiliano Avilés (Fuerza de Acción), José E. Rodó (Motivos de Proteo) que exaltan el papel de la voluntad en la construcción del mundo, como también apartes de la obra de Miguel de Unamuno que se referían al tema, fueron leídos por estos sectores. En la parte inicial de la novela, Fuenmayor hace del doctor Patagato en vocero de disquisiciones psicofisiológicas de esta naturaleza, tema que estaba en boga a comienzos del siglo XX, como también lo pone en boca del profesor Colón, quien señala a los familiares de Cosme que su pedagogía estaba fundamentada en la fisiología, pues a partir del funcionamiento del cuerpo humano explicaba química, física, matemática, astronomía, y otras disciplinas que se aprendían en los estudios de bachillerato. La colección completa de la revista Voces (1917-1920), recientemente reeditada muestra la pasión por estos temas. Aun desde las ideologías contestatarias se insistían en el papel de la acción en la construcción del mundo.

Una literatura de carácter voluntarista que empezando en la filosofía y pasando por lo esotérico terminaba en la poesía y la novela, también permitía colegir las características de lo que José Ingenieros llamó «el hombre mediocre»: la inactividad, la falta de carácter, de ingenio, de persistencia, de propósitos, la ausencia de ilusión. En fin, el ambiente cultural letrado de la época discutía sobre el hombre que requería el nuevo siglo y eso guardaba estrecha relación con los estilos de vida de vieja y nueva data que hacían presencia en el mundo urbano colombiano y costeño.

22 Bacca, 1998: 7-24. Solano, 1999: 167-180. 


\section{A MANERA DE CONCLUSIÓN: FORMAS DE VIDA QUE DESAPARECEN}

La lectura de la novela muestra que Cosme es un extraño puente entre unas formas de vida que se hunden y otras que emergen. El pequeño mundo de Don Damián, su familia y del doctor Patagato, erigido en torno a un estilo de vida que exalta el honor, la dignidad, el autoesfuerzo, el trabajo, la educación, la conducta decorosa, el rechazo al escarnio público. Estos personajes, al tiempo que pueden compartir con las gentes de más abajo muchos aspectos sociales y culturales, se diferencian por ese estilo de vida más acabado y elaborado. En la actitud de Don Damián frente a la voracidad del capital que lo despoja de su pequeño negocio y de los utensilios que empleaba en la elaboración de las fórmulas médicas para los pacientes del doctor Patagato, se puede leer las actitudes de esos actores sociales que entraban en crisis y veían desaparecer los estilos de vida en que habían crecido. El progenitor de Cosme no escucha las sugerencias del médico amigo para que entablara pleito y prefirió asumir con mucha resignación el despojo que llevó a cabo la casa comercial Richardson and Williamson.

Pero su reacción también denota el profundo temor que sentían algunos sectores sociales frente al escándalo público pues ello traía el desmedro de la consideración social de los demás. Germán Colmenares lo advirtió hace más de tres lustros al señalar que el orden social colonial en buena medida estaba construido sobre ese temor, pues el escándalo convertía en hecho público las conductas familiares y privadas, y con ello se desmoronaba el frágil reconocimiento social alcanzado a través de ingentes sacrificios personales y familiares. El escándalo público estaba en contravía con unas formas muy particulares de valorar la vida en sociedad y la valía individual de las personas y por consiguiente de las familias, pues en esa época no se distinguía entre individuo y su forma societaria más inmediata, el núcleo familiar. Todo lo que afectara el reconocimiento social del individuo tocaba la fibra más íntima de la consideración social alcanzada por la familia por medio de un sostenido forcejeo de varias generaciones que se habían esforzado en granjearse una posición digna y honorable en el concierto social.

Se trata de unos estilos de vida de familias enteras que se movían con dificultad en el límite de la sutil línea que separaba el reconocimiento decoroso de la caída en desgracia. Les ha costado ingentes esfuerzos ganarse el aceptación de los de arriba, de sus similares y el respeto de los de abajo, y frente a unos como a los otros, diariamente enfatizaban en el honor, la dignidad y reaccionaban con mucha preocupación ante todo aquello que amenazara con colocarlo en entredicho. 
Sobre estas formas de vida la novela también expone otras aristas del mundo social de ese sector social medio que representaba Don Damián. Él, doña Ramona, madre de Cosme, y el doctor Patagato, su padrino de bautismo, muestran una permanente preocupación por la educación del niño, por la selección del colegio, por inculcarle unos valores en los que la educación desempeña un papel central. Las recientes investigaciones de la historia social subrayan las actitudes de esos sectores medios y de algunas franjas de los sectores bajos por procurarse los mecanismos de movilidad social como la educación en el primer siglo de vida republica que podía garantizar la consideración de los demás. «Solo quien estudia llega a ser alguien en la vida», era un apotegma que estaba muy presente en aquellos sectores que hacían gala de ingentes esfuerzos («hacer de tripas corazones» como se dice en Colombia) por educar a sus hijos. Es una actitud que se refiere directamente al refrán «estudie para que sea alguien en la vida».

Frente a la degradación de este estilo de vida las reacciones fueron diversas acorde con la procedencia familiar, la condición étnica, el estatus de sus oficios, las aspiraciones, sus proximidades o lejanías con los sectores de más abajo y con las elites, en fin, en concordancia con la diversidad del capital simbólico que se poseyera. Esa defensa tuvo una gradación en concordancia con los cambios que se venían operando, pues por una parte el primer lustro de los años de 1920 fueron los de la llamada «prosperidad a debe» y se produjo una movilidad social fundada en la riqueza material, la que era muy mal vista por las elites tradicionales. Además, son los años de un crecimiento demográfico gracias a los sectores de población del campo de casi todo el país, y esto imposibilitó conocer la ascendencia de los recién llegados, grave problema para sectores raizales habituados a tener ese conocimiento pendiente al momento de catalogar socialmente a personas, familias y grupos.

Los nuevos canales de movilidad social y política que se abrieron gracias a la riqueza material y a que los recién llegados ingresaron a las redes de clientela de nuevos actores de la vida política, entre los sectores que empezaron a sentirse amenazados y desplazados pudo haber afianzado una lectura del orden social basada en la prestancia, con sus correlativas prácticas de exclusión y marginación. Durante varios decenios muchas familias se apertrecharon en esa escala de valoraciones sociales y defendieron sus estatus sociales frente a la nueva prestancia por riqueza material, a la que siempre contraponían lo que consideraban el mayor patrimonio de cualquier ser humano: dignidad, honradez, esfuerzo familiar, trabajo, estudio, decoro, el no escandalizar a la sociedad. Así se conservaron con orgullo y altivez, sin someterse y sin aceptar afrentas. Otras que formaban la franja de los parientes pobres de las elites, vivieron con unas prestancias prestadas y a la sombra de sus consanguíneos co- 
laterales, y se caracterizaron por su arribismo y por sus actitudes ofensivas frente a los demás, y constituyeron un baluarte en la defensa de la prestancia por nacimiento. Muchas otras cayeron en desgracia y trasegaron de la pobreza a la miseria sin oponer tenaz resistencia, estados que marcaban una diferencia significativa en una época en la que con mucha vergüenza algunos sectores aceptaban ser declarados «pobres de solemnidad» para poder recibir una pequeña ayuda de las autoridades y así evitar caer en la condición de miserables, el último peldaño de la estratificación social.

En lo esencial se trataba de un frágil estatus de índole familiar conservado con mucho celo y que implicaba diseñar estrategias colectivas para mantenerlo y/o mejorarlo. Estudio, trabajo, procesos de desnegramiento entre las familias de color mediante las conocidas estrategias de «mejorar la raza», de «lavarse», como se estila decir aún hoy, a través de matrimonios con personas de menos pigmentación en la piel, o de aclararse a la sombra, fueron algunos de los mecanismos empleados para mantener o mejorar un poco esa calidad social. La variada escala de pigmentación que entre el negro y el blanco establecía una amplia gama de matices constituía un acervo del que echaban mano diversos sectores para defender sus estatus sociales. Si esto se acompañaba con la puesta en escena de una vida pública virtuosa (trabajo, educación, buenas maneras, recato, etc.) mucho mejor.

El traspié de algún miembro de la familia podía enlodar la dignidad de la misma y llevarla a perder la consideración y estima de los demás. Debido a esto muchas cabezas de familia se mantenían en continua guardia y levantaban a sus hijos y parientes con rigor, con mano dura, pues, para ilustrar con un ejemplo, en un medio social en el que primaba las uniones libres siempre se corría el riesgo de que una joven de la familia se «saliera a vivir» con un fulano de tal considerado de menos condición social y que esta decisión arrastrara a la deshonra a sus parientes. De ahí que «la legitima defensa del honor personal y familiar» era una figura contemplada en la legislación penal que en ciertos casos permitía que los mayores procedieran por vías de hecho contra quienes mancillaban la dignidad. La novela Crónica de una muerte anunciada de Gabriel García Márquez está construida en torno al drama que vive un hombre recién casado que siente ultrajada su hombría porque su esposa no llega virgen al matrimonio, y la tragedia que suscita la familia de esta con el asesinato del hombre que les ultrajó el honor, lo que constituía un acto simbólico para el resto de la sociedad que esperaba de esta manera que la familia mancillada mantuviera la consideración de los demás.

En fin, podemos concluir que la novela Cosme plantea aspectos básicos para quienes se interesan en la historia social urbana del Caribe colombiano de penúltimo tránsito finisecular, al sugerir la existencia de unas relaciones entre 
las ocupaciones laborales, los estilos de vida y las trasformaciones que estas vivieron en el contexto de tránsito a la sociedad capitalista en los centros urbanos costeños. Se trata de un aspecto de vital importancia para entender cómo ha sido el proceso de configuración de la sociedad moderna en la región Caribe colombiana, dado que su estudio muestra una parte importante de la dinámica que asume lo popular como un campo de fuerzas que continuamente colisionan, originando procesos que ayudan a construirlo como un hecho social polisémico, con tensiones y conflictos en torno a los significados que se le dé, como también de los sectores sociales calificados y autocalificados como tales, y de los esfuerzos realizados por algunas franjas de la población para salir del estado de indiferenciación social que ese concepto implica, o por no caer en ella.

\section{BIBLIOGRAFÍA}

Aguilera, Mario, La insurgencia urbana en Bogotá, Bogotá, Colcultura, 1997.

Ardila, Alba, «Educación e ideología en Cosme de José Félix Fuenmayor», Colombia y el Caribe. XIII congreso de colombianistas, Barranquilla, Universidad del Norte, 2005: 382-290.

Bacca, Ramón, Escribir en Barranquilla, Barranquilla, Universidad del Norte, 1998.

Bell, Gustavo, «Cosme o una introducción al siglo XX de Barranquilla», Huellas, 2 (1981): 45-81.

Bobadilla, Emilio (Fray Candil), A fuego lento, Barranquilla, Eds. Gobernación del Atlántico, 1993.

Brown, Jonathan, «La tradición cortés en la cultura colombiana del siglo XIX», Revista Colombiana de Educación, 30 (1995): 5-25.

Coronel, Juan, Un peregrino, Cartagena, Oficina de Extensión Cultural del Departamento, 1947.

Deas, Malcolm, Del poder y la gramática, Bogotá, Tercer Mundo, 1993.

Díaz, Arcadio, «Fernando Ortiz y Allan Kardec: transmigación y transculturación», Gabriel Restrepo, Jaime Eduardo Jaramillo y Luz Gabriela Arango (eds.), Cultura, política y modernidad, Bogotá, Universidad Nacional, 1998: 172-195.

Don Ramiro, Mis entrevistas, Barranquilla, El Comercio, 1928.

Fuenmayor, Alfonso, Crónicas sobre el Grupo de Barranquilla, Bogotá, Colcultura, 1878.

Fuenmayor, José Félix, Cosme, Bogotá, Carlos Valencia Eds., 1979. 
García, Jorge, Retratos de médicos. Crónicas sobre médicos del Bolívar grande en el siglo XIX, Cartagena, Gobernación del departamento de Bolívar, 2000.

García, Jorge, El pensamiento médico selección de textos médicos (1890-1940), Cartagena, Gobernación de Bolívar, 2000.

Garrido, Margarita, «Honor, reconocimiento, libertad y desacato: sociedad e individuo desde un pasado cercano», Gabriel Restrepo, Jaime Eduardo Jaramillo y Luz Gabriela Arango (eds.), Cultura, política y modernidad, Bogotá, Universidad Nacional, 1998: 99-121.

Gilard, Jacques, «El Grupo de Barranquilla», Revista Iberoamericana, 50/128-129 (Pittsburg, 1984): 906-935.

Gilard, Jacques, Entre los Andes y el Caribe. La obra americana de Ramón Vinyes, Medellín, Universidad de Antioquía, 1989.

Goenaga, Miguel, Lecturas locales, Barranquilla, Imp. Departamental, 1953.

Gutiérrez, Francisco, Curso y discurso del movimiento plebeyo en Colombia 1849-1854, Bogotá, El Ancora Eds., 1995.

Guerrieri, Kevin, Palabra, poder y nación. La novela moderna en Colombia 1896-1927, Ciudad de Juárez, Universidad Autónoma de Ciudad de Juárez, 2004.

Helg, Aline, «Sociedad y raza en Cartagena a fines del siglo XVIII», Meisel, Adolfo y Calvo, Haroldo (eds.). Cartagena de Indias en el siglo XVIII, Cartagena, Banco de la República-Universidad Jorge Tadeo Lozano, 2005: 319-364.

Jiménez, David, Historia de la crítica literaria en Colombia, Bogotá, Universidad Nacional-Colcultura, 1992.

Jiménez, David, Fin de siglo. Decadencia y modernidad, Bogotá, Universidad Nacional-Colcultura, 1996.

Lemaitre, Daniel, Poesías y corralitos de piedras, Bogotá, Corporación Financiera del Norte, 1983.

Padilla, Iván, El debate de la hispanidad en Colombia en el siglo XIX, Bogotá, Universidad Nacional, 2008.

Parker, David, «Los pobres de la clase media: estilo de vida, consumo e identidad en una ciudad tradicional», Aldo Panchifi y Felipe Portocarrero (eds.), Mundos interiores: Lima 1850-1950, Lima, Universidad del Pacífico, 1995: 161-185.

Peña, María, «Adolfo Sundheim Lindeman y el triángulo Barranquilla-Bremen-Huelva», Historia y Sociedad, 17 (Medellín, 2009): 97-119.

Pöppel, Hubert, Tradición y modernidad en Colombia. Corrientes poéticas en los años veinte, Medellín, Universidad de Antioquía, 2000.

Recopilación de leyes del Estado Soberano de Bolívar 1857-1875. Cartagena, Imp. A. Araujo, 1876. 
Revollo, Pedro María, Mis memorias, Barranquilla, ed. Mejoras, 1998.

Rivero, Maryelis, Laboratorio Román: origen de la industria farmacéutica en Colombia 1835-1900, Cartagena, Universidad Tecnológica de Bolívar, 2005.

Sewell, William jr., Trabajo y revolución en Francia. El lenguaje del movimiento obrero desde el antiguo régimen hasta 1848, Madrid, Taurus Eds., 1992.

Solano, Sergio Paolo, «Trabajo y ocio en el Caribe colombiano 1880-1930», Historia y Cultura, 4 (1996): 61-76.

Solano, Sergio Paolo, «Política e intelectuales en el Caribe colombiano durante la Regeneración (1886-1899)», IV Seminario Internacional de Estudios del Caribe. Memorias, Bogotá, Universidad del Atlántico, 1999: 167-18.

Solano, Sergio Paolo, «Imprentas, tipógrafos y estilos de vida en el Caribe colombiano, 1850-1930», Palobra, 9 (2008): 126-145.

Solano, Sergio Paolo, «Modelos bipolares, estilos de vida y capas medias n la historiografía social colombiana sobre el siglo XIX», Clío América, 3 (6) (2009): 193-213.

Sundheim, Adolfo, Fruta tropical, Madrid, imp. de J. Blass y cía., 1919.

Tedio, Guillermo, «La pedagogía del fracaso en Cosme», La Casa de Asterión, 17 (2004). www.lacasadeasterion.com (Consulta: febrero 23 de 2006).

Williams, Raymond, Novela y poder en Colombia 1844-1987, Bogotá, Tercer Mundo eds., 1991.

Fecha de recepción: 5 de octubre de 2009

Fecha de aceptación: 19 de septiembre de 2010 


\section{Social history and literature in early-20 $0^{\text {th }}$ century Colombia. The middle class in José Félix Fuenmayor's novel Cosme}

Based on the indexical method proposed by Carlo Ginzburg, this article focuses on the novel Cosme in order to analyze the aspects of the underlying social context within the novel. From the outer concentric circles made by what little we know about the life of José Félix Fuenmayor, the authors travel to the world of the characters in the novel, showing that there are certain aspects which are very close to the author's personal and family life. They reconstruct certain aspects of the sociocultural fabric of Barranquilla in the early $20^{\text {th }}$ century, especially the middle class layers that were organized around a lifestyle in which the projection of a socially valued image was essential.

KEY WORDS: Novel; history; life styles; honor; capitalism; middle class layers; handcraft trades; Barranquilla. 